\title{
Direct and heterologous approaches to identify the LET-756/FGF interactome
}

\author{
Cornel Popovici, Yael Berda, Fabien Conchonaud, Aurélie Harbis, \\ Daniel Birnbaum and Régine Roubin*
}

Address: Institut de Cancérologie de Marseille, Laboratoire d'Oncologie Moléculaire, Institut Paoli-Calmettes et UMR599 INSERM, 27 Bd. Leï Roure, 13009 Marseille, France

Email: Cornel Popovici - popovici@marseille.inserm.fr; Yael Berda - yaelberda@yahoo.com; Fabien Conchonaud - conchonaud@ciml.univmrs.fr; Aurélie Harbis - aurelie_harbis@yahoo.fr; Daniel Birnbaum - birnbaum@marseille.inserm.fr;

Régine Roubin* - roubin@marseille.inserm.fr

* Corresponding author

Published: 03 May 2006

BMC Genomics 2006, 7:105

doi:10.1I86/|47|-2|64-7-105
Received: 13 January 2006

Accepted: 03 May 2006

This article is available from: http://www.biomedcentral.com/147I-2164/7//05

(C) 2006 Popovici et al; licensee BioMed Central Ltd.

This is an Open Access article distributed under the terms of the Creative Commons Attribution License (http://creativecommons.org/licenses/by/2.0), which permits unrestricted use, distribution, and reproduction in any medium, provided the original work is properly cited.

\begin{abstract}
Background: Fibroblast growth factors (FGFs) are multifunctional proteins that play important roles in cell communication, proliferation and differentiation. However, many aspects of their activities are not well defined. LET-756, one of the two C. elegans FGFs, is expressed throughout development and is essential for worm development. It is both expressed in the nucleus and secreted.
\end{abstract}

Results: To identify nuclear factors associated with LET-756, we used three approaches. First, we screened a two-hybrid cDNA library derived from mixed stages worms and from a normalized library, using LET-756 as bait. This direct approach allowed the identification of several binding partners that play various roles in the nucleus/nucleolus, such as PAL-I, a transcription regulator, or RPS-16, a component of the small ribosomal subunit. The interactions were validated by coimmunoprecipitation and determination of their site of occurrence in mammalian cells. Second, because patterns of protein interactions may be conserved throughout species, we searched for orthologs of known mammalian interactors and measured binary interaction with these predicted candidates. We found $\mathrm{KIN}-3$ and $\mathrm{KIN}-10$, the orthologs of CK2 $\alpha$ and CK2 $\beta$, as new partners of LET-756. Third, following the assumption that recognition motifs mediating protein interaction may be conserved between species, we screened a two-hybrid cDNA human library using LET-756 as bait. Among the few FGF partners detected was I4-3-3 $\beta$. In support of this interaction we showed that the two I4-3-3 $\beta$ orthologous proteins, FTT-I and FTT-2/PAR-5, interacted with LET-756.

Conclusion: We have conducted the first extensive search for LET-756 interactors using a multidirectional approach and established the first interaction map of LET-756/FGF with other FGF binding proteins from other species. The interactors identified play various roles in developmental process or basic biochemical events such as ribosome biogenesis.

\section{Background}

FGFs constitute a superfamily of pleiotropic growth fac- tors involved in multiple cellular processes such as mitogenesis, angiogenesis and mesoderm induction [1]. 
There are 22 FGFs in humans. Except FGF11-14, they exert their biological activities by acting as extracellular growth factors binding to receptors (FGFR1-4) of the tyrosine kinase receptor superfamily [2]. In addition, FGF1-3 and FGF11-14 are localized in the nucleus and function intracellularly [3]. Intracellular FGFs bind to several proteins that play a role in FGF trafficking: FIBP, which allows FGF1 to shuttle between the cytosol and the nucleus [4], synaptotagmin-1, which allows FGF1 exocytosis [5], Cystein Rich FGF receptor (CFR), which forms complexes with various FGFs and allows their secretion [6,7], and LRP-1 and 2 (lipoprotein receptor-related proteins), which in conjunction with DAB-1 (Disabled) regulate EGL-17/FGF export in C. elegans [8]. FGF interactors may also regulate FGF nuclear activity; this is the case of Casein Kinase II regulatory subunits [9] and splicing factor SF3a66 [10], which both interact with FGF2. Finally, proteins of the extracellular matrix such as fibstatin and fibrinogen interact with FGF2 [11,12].

LET-756 is one of the two FGFs of C. elegans [13, 14 for reviews]. It is essential for worm development [15]. Like some mammalian FGFs, it acts both intra and extracellularly. The molecular motif allowing secretion [16] and some of LET-756 extracellular functions have been described $[17,18]$ but the intracellular functions remain poorly defined, although nuclear localization is probably of importance [19]. To further characterize the functions of LET-756, we used yeast two-hybrid screens to identify proteins that interact with this FGF. We identified several interacting proteins involved in various developmental processes or in basic biochemical events such as ribosome biogenesis, and validated some of the interactions by coimmunoprecipitation and/or colocalization.

\section{Results \\ Identification of nematode LET-756 binding proteins by yeast two-hybrid library screens}

To identify worm proteins that interact with LET-756, we used the two-hybrid system in the MAV103 yeast with LET-756 fused to the Gal-4 DNA binding domain (pDB) as bait and two C. elegans libraries. The latter were either normalized [20] to contain one representative of each expressed gene of the whole genome (ORFeome) or derived from a mixed stage worm population. Library clones were coupled to the Gal-4 activating domain (pAD). The bait did not show any intrinsic transcriptional activation of the three yeast reporter genes. In a screen of approximately $4 \times 10^{6}$ transformants, 41 clones were positive for the two reporters tested, or for only one reporter but with great intensity. The gap repair technique confirmed 9 clones (Table 1). Sequencing of these clones and blastn or tblastx interrogation of databases revealed unidentified sequences (UIS) and sequences coding for proteins with known functions: UMP synthase, an enzyme involved in de novo nucleic acid synthesis, cathepsin (aspartic peptidase A1, pepsinogen family member), RPS16 (small ribosomal subunit), transcription factor PAL-1 involved in the anterior-posterior development of the male [21], DAF-21, a chaperone of the HSP-90 family, involved in chemosensory transduction and insulin signalization [22,23], COL-129, an isoform of collagen, and SKR-2 (homolog of skp1 of S. cerevisiae), a component of the skp1p/cullin/F-box SCF complex with ubiquitin ligase activity $[24,25]$. The latter also shows similarities with P19, which is associated with cyclinA/CDK2 complex in humans.

To confirm the results on some on the interactors we judged potentially relevant, pAD interactor clones were picked individually from the ORFeome library and tested directly in yeast two-hybrid system against pDB LET-756. PAL-1 interacted strongly with LET-756 (two positive tests). For the other interactors, only one test was clearly positive (Table 2A).

\section{Identification of LET-756-binding proteins among orthologs of known mammalian FGF interactors}

The conservation of signaling pathways between worms and mammals, as well as the conserved FGF structures in different species [26,27], suggested that orthologs of human FGF-binding proteins could interact with LET756. We used blast interrogation to determine the most conserved orthologs supposed to retain the ancestral function of the known human FGF-interactors. These orthologs were recovered from the ORFeome library and tested in binary interactions (Table 2B). We found kin-10 (CK2 $\beta$ ) and rpl-6 positive for two reporter genes, and kin3 (CK2 $\alpha$ ), hsp-6 (mortalin), F14E5.2 (cystein rich FGF receptor, CFR) and $\mathrm{C} 18 \mathrm{~A} 3.3$ (NoBP) positive for one reporter gene.

\section{Identification of human LET-756-binding proteins}

We based our third approach on the assumption that protein interaction motifs may be conserved between species. We made a heterologous screen using a cDNA human library as prey and LET-756 as bait. The yeast two-hybrid system was used with LET-756 fused to LexA DNA binding domain as bait (pDB) for the screening of a human placenta cDNA library containing the Gal-4 activating domain (pAD). Table 3 indicates the number of times the interactors were isolated and the strength of the interaction. Identified partners were different from those unveiled by the C. elegans screens but showed similar biologic activities (Table 4). MBD1 and ZN420 are transcription factors, 14-3-3 $\beta$ (YWHAB, tyrosine 3monooxygenase/tryptophan 5-monooxygenase activation protein, $\beta$ polypeptide) has chaperone activity, and FBLI1 (Filamin-binding LIM protein 1) is a protein of the Zyxin family. 
Table I: LET-756-interacting proteins identified by screening Y2H C. elegans libraries. Bait used was DB-LET-756. Sequences of ADinteractor clones are in (58). Clones were assigned scores for LacZ expression, growth on plates lacking histidine but containing 20 or $40 \mathrm{mM}$ 3-amino triazol (3-AT) and in addition, growth on plates lacking uracil (URA) for the $C$. elegans libraries

\begin{tabular}{|c|c|c|c|c|c|c|c|}
\hline $\begin{array}{l}\text { Interactor } \\
\text { (sequence } \\
\text { name) }\end{array}$ & Gene name & Human ortholog(s) & LacZ & $\begin{array}{l}\text { 3-AT } 20 \\
\text { mM }\end{array}$ & $\begin{array}{l}\text { 3-AT } 40 \\
\text { mM }\end{array}$ & URA & Library \\
\hline AD-C38D4.6 & pal-I & $\begin{array}{l}\text { CDX4 (Caudal-type homeobox } \\
\text { protein 4) }\end{array}$ & ++ & + & - & - & cDNA \\
\hline AD-C47E8.5 & daf-2I & HSP90 family & - & ++ & + & - & cDNA \\
\hline AD-T0IC3.6 & rps-16 & RPSI6 (40S ribosomal protein SI6) & $+/-$ & ++ & - & - & cDNA \\
\hline AD-T07C4.I & - & UMPS (UMP-synthase) & - & $+/-$ & - & ++ & cDNA \\
\hline AD-CI5C8.3 & - & CTSE (Cathepsin E precursor) & $+/-$ & + & - & - & cDNA \\
\hline$A D-C I 5 C 6.2 b$ & $\mathrm{Cl} 15 \mathrm{C} 6.2$ & - & - & + & + & - & cDNA \\
\hline AD-MI8.I & col-I 29 & $\begin{array}{l}\text { COL4A5 (Collagen alpha } 5(\mathrm{IV}) \text { chain } \\
\text { precursor) }\end{array}$ & $+/-$ & + & $+/-$ & - & cDNA \\
\hline AD-F35A5.4 & - & $\begin{array}{c}\text { KRTAPI0-4 (Keratin-associated } \\
\text { protein 10-4) }\end{array}$ & + & - & - & - & AD-ORFeome \\
\hline AD-F46A9.4 & $s k r-2$ & $\begin{array}{l}\text { SKPIA (S-phase kinase-associated } \\
\text { protein IA) }\end{array}$ & $+/-$ & ++ & - & - & AD-ORFeome \\
\hline
\end{tabular}

Finally, the orthologs of human 14-3-3 , ftt-1/par-5 and $f t t-2$, and the orthologs of FBL1, $z y x-1 a$ and $z y x-1 b$, were obtained from the nematode ORFeome library and tested for direct interaction in yeast two-hybrid system. Table $2 \mathrm{C}$ indicates that FTT-1 and FTT-2, but not ZYX-1a or ZYX-1b, reacted with the LET-756 bait.

\section{Confirmation of interactions by co- immunoprecipitation experiments}

A number of interactors we identified have been described as false positives in various studies. It is the case for HSP family members and ribosomal proteins, and to some extent for collagen-related proteins, $\mathrm{Zn}$ finger proteins and proteasome subunits [28]. To validate the interaction of LET-756 with the candidate partners, co-immunoprecipitation experiments were done in Cos- 1 cells. Cos- 1

Table 2: Direct interactions between LET-756 (DB) and clones derived from the ORFeome library. A) clones detected in the screening of the C. elegans libraries; B) orthologs of clones detected in the screening of the human placenta library; C) orthologs of known mammalian FGF interactors.

Interactors (AD)

\begin{tabular}{|c|c|c|c|c|}
\hline & & LacZ & 3-AT & URA \\
\hline \multirow[t]{6}{*}{$A$} & RPS- 16 & $+/-$ & ++ & - \\
\hline & PAL-I & ++ & + & - \\
\hline & DAF-2I & - & $+*$ & - \\
\hline & COL-129 & $+/-$ & + & - \\
\hline & SKR-2 & $+/-$ & $+/-$ & - \\
\hline & $\mathrm{CI} 5 \mathrm{C} 6.2$ & $+/-$ & + & - \\
\hline \multirow[t]{6}{*}{ B } & KIN-I0 (CSNK2B, CK2ß) & $+1-$ & + & - \\
\hline & KIN-3 (CSNK2A, CK2 2 ) & - & + & - \\
\hline & HSP-6 (HSPA9B, mortalin) & - & + & - \\
\hline & FI4E5.2 (GLGI, CFR) & - & $+1-$ & - \\
\hline & CI8A3.3 (EBNAIBP2, NoBP) & - & $+/-$ & - \\
\hline & RPL-6 (RPL6) & $+/-$ & + & - \\
\hline \multirow[t]{3}{*}{ C } & FTT-I/PAR-5 (YWHAB, I4-3-3ß) & $+/-$ & + & - \\
\hline & FTT-2 (YWHAB, I4-3-3ß) & $+/-$ & + & - \\
\hline & ZYX-Ia, ZYX-Ib (ZN420) & - & - & - \\
\hline
\end{tabular}

*: 3-AT concentration allowing yeast growth was $20 \mathrm{mM}$ except for DAF-2I where it was $40 \mathrm{mM}$ 
Table 3A: LET-756-interacting proteins identified by screening Y2H human placenta libraries. A: Number of times the clone was detected during the $\mathrm{Y} 2 \mathrm{H}$ library screening and scores for the different reporter genes.

\begin{tabular}{|c|c|c|c|c|c|}
\hline \multirow[t]{2}{*}{ Interactor } & \multirow[t]{2}{*}{ times } & \multicolumn{4}{|c|}{ LET-756 } \\
\hline & & lacZ & His-3 & 3-AT (20 mM) & 3-AT $(40 \mathrm{mM})$ \\
\hline YWHAB (14-3-3 $\beta)$ & 11 & + & + & - & - \\
\hline MBDI & 1 & + & + & - & - \\
\hline EIF3S2 (eiF3) & i & + & + & - & - \\
\hline FBLPI & I & + & + & - & - \\
\hline KRABI00 & 3 & + & + & + & + \\
\hline
\end{tabular}

*: 3-AT concentration allowing yeast growth was $20 \mathrm{mM}$ except for DAF-2I where it was $40 \mathrm{mM}$

cells were transiently cotransfected with HA-tagged partner constructs and LET-756::GFP, and the lysates were immunoprecipitated with anti-GFP. Fig. 1 shows the result of a western blot probed first with anti-HA to reveal the co-immunoprecipitated proteins, and second with anti-GFP to normalize the transfection with LET-756. All tested partners immunoprecipitated with LET-756, although with different strength, unrelated to their level of expression (not shown). The 14-3-3 $\beta$ and KIN-10 proteins were reproducibly the less efficient. To make sure that overexpression of the two tagged proteins was not responsible for the immunoprecipitation, we used TACC1 as an unrelated HA-tagged control. In similar condition, TACC1 was unable to immunoprecipitate LET-756.

\section{Confirmation of interactions by subcellular colocalization experiments}

To further confirm FGF/partner interaction in mammalian cells, HA-tagged partners were co-expressed with LET756::GFP in Cos-1 cells and their respective subcellular localization was examined. As already described [16,19], LET-756::GFP localized in specific regions of the nucleus where splicing factors are concentrated. Immunofluorescence microscopy using anti-HA antibodies revealed PAL1 in foci in the nucleus that colocalized with LET-756 (Fig. 2 ). We have previously established [19] that treatment of LET-756 expressing cells with actinomycin D (a drug inhibiting Pol I and Pol II activities) displaces LET-756 to the perinucleolar and nucleolar compartments. Addition of actinomycin D did not move the PAL-1 protein to the nucleolus as it did for LET-756 but kept both partners in close association in nucleoplasmic foci. Other partners, such as RPL-6, were delocalized by transfection of LET756. RPL- 6 was localized in large foci mainly in the nucleoplasm when transfected alone (column I, Fig. 2) but was most often dispersed through the nucleoplasm and associated with LET-756 when cotransfected with the FGF (Fig. 2, column II to IV). FTT-1/PAR-5 and FTT-2 localized preferentially in the cytoplasm when transfected alone, but observed also in the nucleus when transfected together with LET-756. In addition, vesicles containing both LET756 and FTT-1 or FTT-2 were visible. KIN-3 colocalized with LET-756 in nuclei and exhibited a strong expression in cytoplasm whether LET-756 was present or not whereas KIN-10 present in nucleoplasm of untransfected LET-756 cells moved with LET-756 in the speckles when co-transfected. Upon actinomycin D treatment both LET-756 and KIN-10 formed enlarged speckles and moved to the nucleolus (Fig. 2). This stricking delocalization observed upon actinomycin D treated KIN-10 co-transfected cells did not occurred with KIN-3. In other instances, the partner modified LET-756 localization: RPS-16 concentrated LET-756 in large foci when both proteins were present in the nucleus (Fig. 2). The protein encoded by C15C6.2 did not show any gross colocalization (Fig. 2). Finally, COL-129 was localized only at the Golgi apparatus, whether LET756 was present or not, and CFR was localized only in the cytoplasm.

Table 3B: LET-756-interacting proteins identified by screening Y2H human placenta libraries. B: Description of the proteins and identification of the $C$. elegans ortologs.

\begin{tabular}{|c|c|c|}
\hline Protein & Description & C.elegans orthologs \\
\hline YWHAB (14-3-3ß) & $\begin{array}{l}\text { protein with chaperone activity implicated in subcellular } \\
\text { compartmentalization of binding partners }\end{array}$ & PAR-5 or FTTI, FTT-2 \\
\hline MBDI & negative regulator of transcription, the methyl CpG-Binding Domain & none \\
\hline EIF3S2 & initiator of translation (subunit 9) & EIF3-B \\
\hline FBLII & $\begin{array}{l}\text { protein belonging to the Zyxin family, having } 3 \text { LIM domains, involved } \\
\text { in protein-protein interaction (filamin-binding LIM protein-I) }\end{array}$ & ZYX-I \\
\hline ZN420 & zinc finger protein with a Krab domain & none \\
\hline
\end{tabular}

\footnotetext{
*: 3-AT concentration allowing yeast growth was $20 \mathrm{mM}$ except for DAF-2I where it was $40 \mathrm{mM}$
} 
Table 4: Summary of interaction strengths

\begin{tabular}{|c|c|c|c|c|c|}
\hline Interactors & Y2H- screen & Co-IP & Coloc & Deloc & Class \\
\hline RPS- 16 & ++ & ++ & + & + & I \\
\hline FTT-I & ++ & +++ & - & + & 1 \\
\hline FTT-2 & ++ & +++ & - & + & 1 \\
\hline KIN-IO & ++ & + & + & + & 1 \\
\hline PAL-I & +++ & + & + & + & 1 \\
\hline $\mathrm{CI} 5 \mathrm{C} 6.2$ & ++ & ++ & + & - & II \\
\hline RPL-6 & ++ & ++ & - & + & II \\
\hline DAF-2I & + & ++ & \multicolumn{2}{|c|}{ ND } & III \\
\hline COL- 129 & ++ & + & + & - & III \\
\hline SKR-2 & ++ & ++ & \multicolumn{2}{|c|}{ ND } & III \\
\hline KIN-3 & + & ++ & $+/-$ & - & III \\
\hline Cl8A3.3 & + & ++ & \multicolumn{2}{|c|}{ ND } & III \\
\hline
\end{tabular}

Scores obtained in the different assays used: (i) two-hybrid assays, (ii) co-immunoprecipitation (co-IP), (iii) colocalization by immunofluorescence in single transfected cells (Coloc) and (iv) delocalization (Deloc) of one or the two partners induced by the cotranfection. Interactions were classified as I (the strongest) to III (the weakest).

\section{Discussion}

Several growth factors are found in the nucleus in addition to their other localizations. This is the case for LET756 but not for EGL-17, the other C. elegans FGF [29]. The role of LET-756 in the nucleus is not known. To help characterize this role we searched to identify intracellular binding partners of LET-756. By using different twohybrid screens in yeast, we identified several proteins

Table 5: C. elegans orthologous genes of known human FGF interactors.

\begin{tabular}{|c|c|c|}
\hline FGF & Interactor & C. elegans or human orthologs \\
\hline FGFI & HSPA9B (Stress-70 protein, mortalin) [39] & hsp-6 (C37H5.8) \\
\hline FGFI & $\begin{array}{c}\text { NP_060979.2 (PROI855, LOC55379, ribosome-binding protein p34, } \\
\text { RBP34*) [39] }\end{array}$ & F56A8.3 \\
\hline FGFI & LDL (Low density lipoproteins) [40] & - \\
\hline FGFI & SI00AI3 (Calcium binding protein SIO0AI3) [4I] & - \\
\hline FGFI & SYTI (Synaptotagmin-I) [5] & snt-I (F3 IE8.2) \\
\hline FGFI & FIBP (FGF-I intracellular binding protein) [4] & - \\
\hline FGFI and FGF2 & FGFBPI (Fibroblast growth factor binding protein I) [42] & - \\
\hline FGFI and FGF2 & CSNK2A (Casein Kinase II, catalytic subunit $\alpha$ ) [43] & kin-3 (B0205.7) \\
\hline FGF2 & CSNK2B (Casein Kinase II, regulatory subunit $\beta$ ) [9] & kin-IO (T0IG9.6b) \\
\hline FGF2 & RPL6 (Large ribosomal subunit L6) [36] & $r p l-6(\mathrm{R}|5| .3)$ \\
\hline FGF2 & RPSI9 (40S ribosomal protein S19) [37] & rps-19 (T05FI.3) \\
\hline FGF2 & $\begin{array}{c}\text { CEP57 (Translokin, Centrosomal protein of } 57 \mathrm{kDa} \text {, Proliferation-inducing } \\
\text { protein 8, PIG8) [44] }\end{array}$ & - \\
\hline FGF2 & SMNI (Survival motor neuron protein) $[45,46]$ & smn-I (C4IG7.I) \\
\hline FGF2 & FGA/FGB/FGG (Fibrinogen, alpha/beta/gamma polypeptides) $[12,47]$ & - \\
\hline FGF2 & FNI (Fibstatin, fragment of fibronectin) [II] & $\mathrm{C} 56 \mathrm{Cl} 0.4$ \\
\hline FGF2 & $\begin{array}{l}\text { API5 (Apoptosis inhibitor 5, Fibroblast growth factor 2-interacting factor, } \\
\text { FIF) [48] }\end{array}$ & - \\
\hline FGF2 & SF3A2 (Splicing factor $3 A$ subunit 2$)[10]$ & FIIAI0.2 \\
\hline FGF2 & PTX3 (Long pentraxin 3) [49] & - \\
\hline FGF2 & PF4 (CXC chemokine platelet factor 4) [50] & - \\
\hline FGFI, FGF2, FGF3, FGF4 & $\begin{array}{c}\text { GLGI (Golgi apparatus protein I precursor, Cysteine-rich fibroblast } \\
\text { growth factor receptor, CFR-I) }[6,7]\end{array}$ & FI4E5.2 \\
\hline FGF3 & $\begin{array}{l}\text { EBNAIBP2 (rRNA processing protein EBP2, Nucleolar Binding Protein, } \\
\text { NoBP) [5I] }\end{array}$ & CI8A3.3 \\
\hline FGFII-I4 & MAPK8IP2 (Islet-brain-2, JNK MAP kinase scaffold protein 2) [52] & jip-l (F56DI2.4) \\
\hline EGL-17 & LRP-I (Low-density lipoprotein Receptor Related, F29DI I.I) [8] & Irp-I \\
\hline EGL-17 & LRP-2 (Low-density lipoprotein Receptor Related, T2 IE3.3) [8] & Irp-2 \\
\hline EGL-17 & DAB-I (Drosophila disabled homolog, MII0.5) [8] & dab-l/dab-2 \\
\hline
\end{tabular}

- No approved gene name 


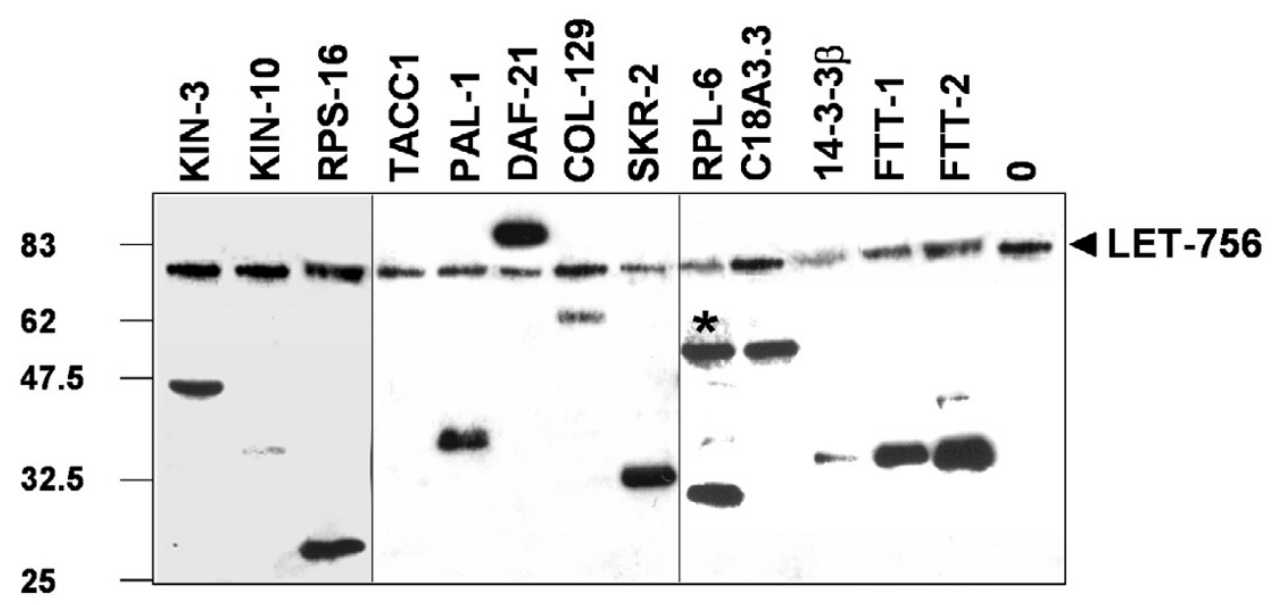

Figure I

Co-immunoprecipitation of LET-756::GFP and HA-tagged protein partners Cos-I cells were transfected with let756::gfp alone (0) and with various HA-tagged constructs presumed or not (TACCI) to interact with LET-756. Twenty four hours later cell lysates were immunoprecipitated with anti-GFP antibodies. Western blots were first revealed with anti-HA antibodies and then with anti-GFP antibodies. An additional band, indicated with an asterisk, was consistently observed with HA- tagged RPL-6. A week and non- reproducible band can also be seen in the FTT-2 co-immunoprecipitation lane. None of these bands arose from possible complexes since I) electrophoresis was performed in denaturating conditions and 2) antibody detection relied on the tag epitope and not on the endogenous protein.

involved in various aspects of protein synthesis or degradation. Further analysis by co-immunoprecipitation and colocalization confirmed the interactions identified. We demonstrated that not only LET-756 could interact with mammalian partners as well as their orthologs (e.g 14-3$3 \beta$ vs FTT-1/PAR-5 and FTT-2) but also that orthologs of mammalian FGF partners could interact with LET-756 (CK2 $\beta$ vs KIN-10). Analyses of these partners could be of interest in the study of mammalian FGFs.

The majority of the proteins we identified are nuclear, which was expected since the two-hybrid system needs the fusion to be targeted to the nucleus. However, some interactions have been identified as false positive in other screens [28]. By performing co-immunoprecipitations and studying subcellular localization, we validated the interaction of LET-756 with RPS-16, FTT-1/PAR-5, FTT-2, KIN-10 and RPL- 6 with high score, and with PAL-1, DAF21, SKR-2, KIN-3 and C18A3.3 with lower strength (see Table 6). The function of some interacting partners is relevant to FGF biology. The 14-3-3/FTT-1/FTT-2 proteins, which belong to the highly conserved family of chaperone molecules transit to the nucleus and participate in nucleocytoplasmic transport, regulating intracellular transduction [30]. We did not find a 14-3-3 conventional phosphorylated binding site on LET-756. However, other domains have been involved in 14-3-3 binding, such as nuclear localization signals ( 31 for review). No role for FTT-1 or FTT-2 in modulating secretion has been assigned in C. elegans. It will be interesting to analyze whether interaction of these proteins with the EFVSVA motif of secretion described in LET-756 [16] causes its secretion. The interaction of LET-756 with PAL-1 is of interest because PAL-1 is also highly conserved during evolution. It is the ortholog of caudal (Drosophila), CDX1, 2 and 4 (mammals) and Xcad3 (Xenopus) paraHOX proteins. Caudal proteins are involved in the transcriptional regulation of multiple genes that are involved in posterior patterning [32]. The interaction of LET-756 with PAL-1 could activate the expression of various genes involved in nematode anterior-posterior development as it is the case for the interaction of Xenopus e-FGF with Xcad3 and the resulting activation of $H O X$ genes [33,34]. In addition, pal-1 mutant exhibits aberrant cell position in posterior muscle cells [35], a site of LET-756 expression [13,19] as well as in posterior hypodermis, a site of LET-756 action [17]. Both muscle and epidermis evolve from the $\mathrm{C}$ lineage. In the absence of PAL-1, the $\mathrm{C}$ blastomeres fail to develop. Protein phosphorylation by the coordinated activities of protein kinases and phosphatases is central to many signal transduction pathways. The combined action of LET-756/FGF, EGL-15 receptor, CLR-1 phosphatase (for a review see [14]) and KIN-3 and KIN-10, the respective catalytic and regulatory subunits of $\mathrm{CK} 2$, might regulate various processes involved in proliferation -as it is described for FGF1 and $2[43,9]-$ or in other functions. KIN-3 and KIN-10 have been recently implicated in primary cilia biology [55]. Finally, some ribosomal proteins 


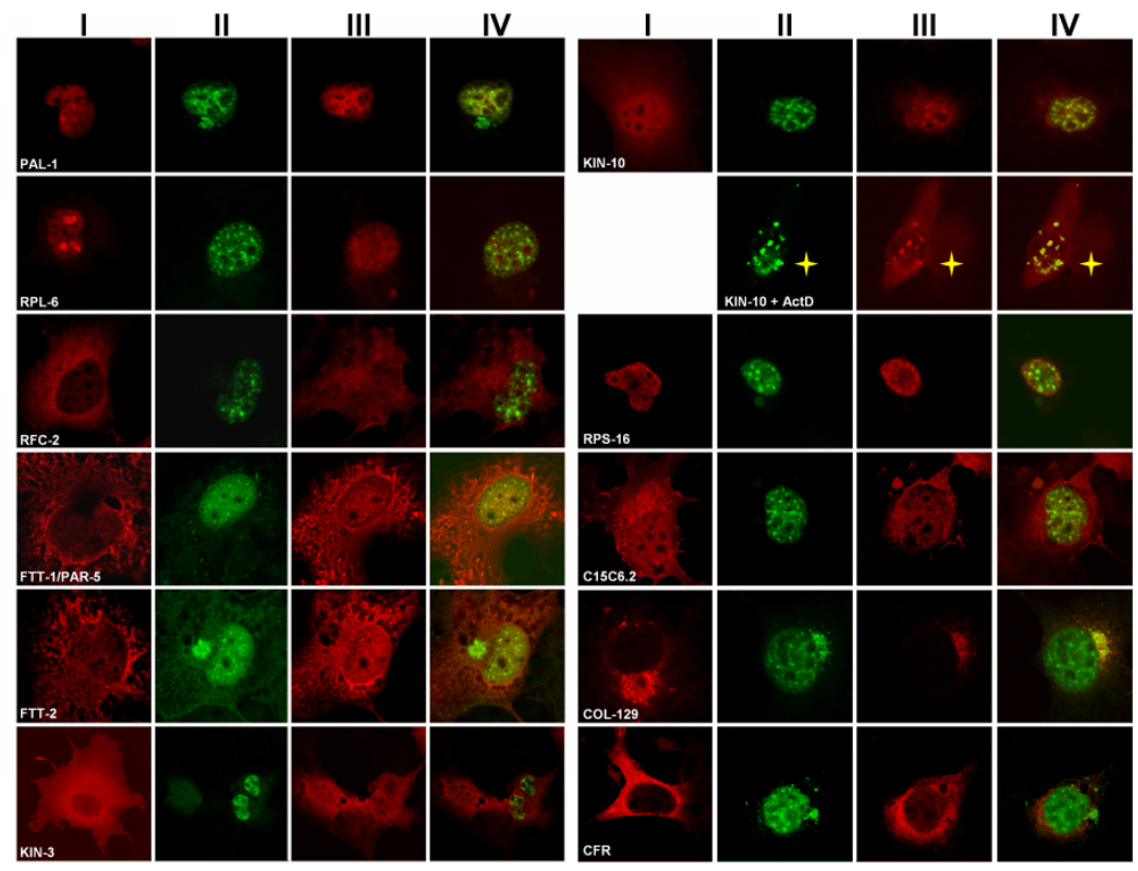

Fig. 2

\section{Figure 2}

Intracellular localization of LET-756::GFP and HA-tagged protein partners Cos-I cells were transfected with let756::gfp with or without various HA-tagged encoded constructs. Twenty four hours later cells were either fixed in $4 \%$ paraformaldehyde and permeabilized in triton or in cold methanol. Cells were incubated for an hour with rat anti-HA antibodies. Secondary goat anti-rat Texas red-coupled antibodies were then added for another $30 \mathrm{~min}$. Coverslips were visualized with a confocal Leica microscope. Cells were transfected with the HA-tagged protein alone (column I) or cotransfected with let756::gfp and revealed by direct fluorescence (column II), by anti-HA immunofluorescence (column III) and merge (column IV). In cells cotransfected with LET-756 and $\mathrm{KIN}-\mathrm{IO}$ and treated with actinomycin D, both GFP staining and anti-HA immunostaining are displaced around and into the nucleolus. The yellow star indicates a neighbor single KIN-I 0 transfected cells. Its localization is not modified by the drugs. Panels $A$ and $B$ each show results for five interactors analyzed.

interact with mammalian FGF [36-38] to regulate their signaling and trafficking to the nucleus; reciprocally, FGFs may regulate ribosome biogenesis and protein synthesis during the G1 phase of the cell cycle. In contrast to these relevant interactors, others appear irrelevant, such as MBD1 since no methylation occurs in C. elegans.

The interactions revealed by the two-hybrid screens are rather weak. This could be due to 1) the high stringency associated with the system using the MAV 103/203 yeast strains; it is worth noting that in large-scale screenings of interactions no partner for LET-756 was found [20]; 2) a bad exposure of the binding site in the fusion proteins; 3 ) the existence of ternary interactions as seen in the ligand - tyrosine kinase receptor - heparan sulphate complex and 4) the need for post-translational modifications of the proteins that occur in mammalian cells and not in yeast, explaining why better interactions between glycosylated LET-756 [16] and various partners were obtained in immunoprecipitation and immunofluorescence experiments than in yeast two-hybrid screens.
Finally, it will be interesting to know whether the expression pattern of LET-756, which is mainly muscular and neuronal in the worm, overlap with that of the various partners. Search in the literature $(56,57)$ was not conclusive since the majority of the partners were found in eggs (FTT-1/PAR-5, FTT-2, DAF-21, PAL-1), intestine (HSP-6, SKR-2) or cuticle (COL-129).

\section{Conclusion}

We have conducted the first extensive search for LET-756 interactors and established the first interaction map of LET-756/FGF with FGF binding proteins (Fig. 3 and Table $6)$. This could help understand FGF functions. Proteins of interest were involved in developmental processes or in basic biochemical events such as ribosome biogenesis and protein synthesis. In addition, to get insight in the evolution of the FGF interactome network, which we have illustrated in Fig. 3, we tested 6 of 20 orthologs of human FGF interactors (Table 6), and found KIN-10 and RPL-6 as new potential interactors. Looking for physical interactions in 


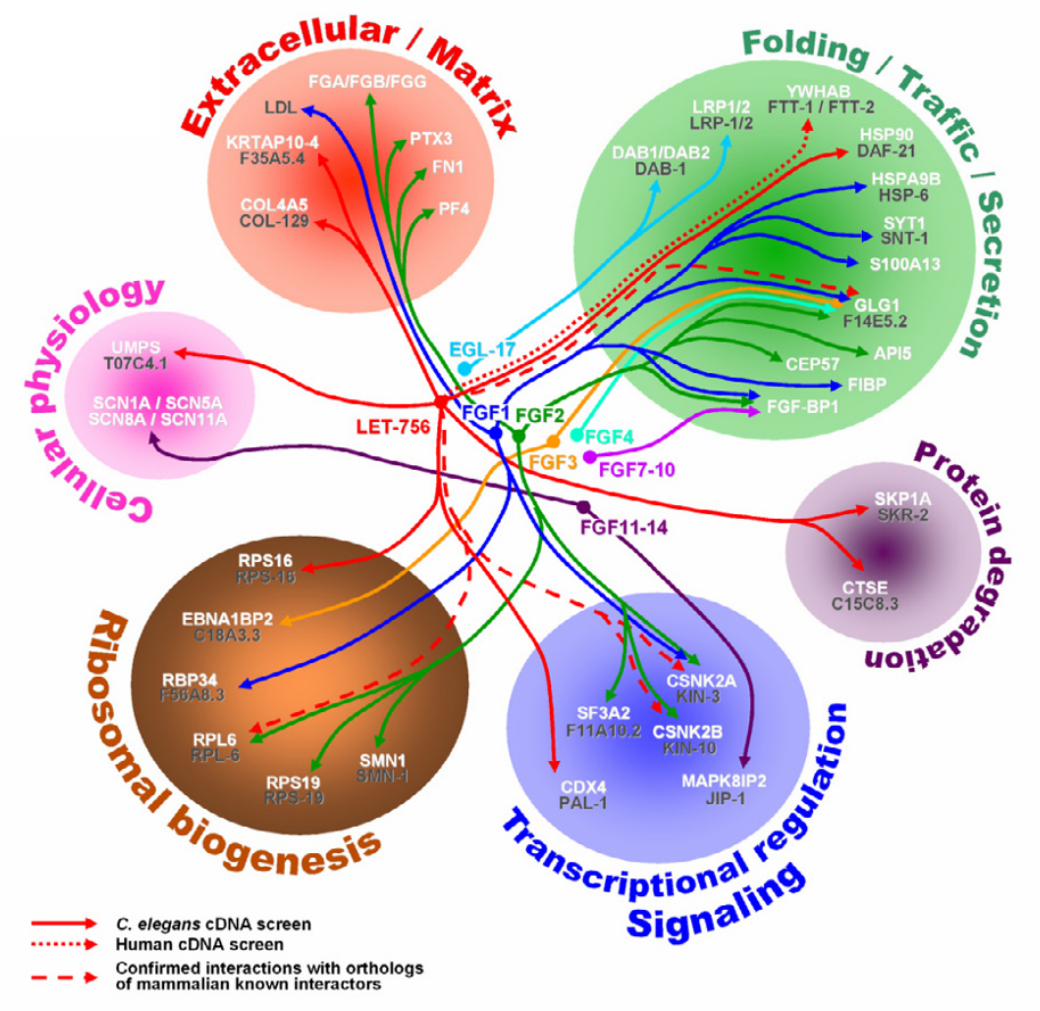

Figure 3

Interactome of the FGF family The identified interactors of various FGFs were grouped in six categories, depending of the functional activities of proteins. The human and C. elegans orthologs are indicated: human (white), worm (grey).

a physiological system will determine which of these interactions are essential.

In conclusion, 1) combining the yeast two-hybrid screen with bioinformatics and computational biology, we have delineated potential interactors of LET-756, and possibly of the entire FGF family; 2) comparative genomics analysis yielded valuable insights into conserved and divergent aspects of function, regulation, and evolution since not all pathways are conserved as demonstrated by the ortholog analysis; 3) the information given herein, although not complete, might be useful for people working in the field.

\section{Methods}

\section{Yeast two-hybrid assays}

A full-length let-756 transcript was fused in-frame with the coding sequence of the DNA binding domain (DB) of Gal4, and was used in a $\mathrm{Y} 2 \mathrm{H}$ screen system as described in [20] for the $C$ elegans libraries. Two worm libraries fused to the activation domain (AD) of Gal4, a cDNA and the AD-ORFeome libraries [53] were screened. The MAV103 yeast strain based $\mathrm{Y} 2 \mathrm{H}$ assay contains three reporter genes
(HIS3, lacZ and URA3) [54]. A cDNA human placenta library fused to the activation domain of LexA was also screened. The L40 yeast strain based $\mathrm{Y} 2 \mathrm{H}$ assay contains only two reporters (HIS3 and lacZ). In this case, the full length let-756 transcript was cloned into the LexA DNA binding domain bait expression vector pBTM116B Kana. Yeast assays were done using conventional lithium acetate-based method. Clones were assigned scores for LacZ expression, growth on plates lacking histidine but containing 20 or $40 \mathrm{mM}$ 3-amino triazol and in addition, growth on plates lacking uracil for the C. elegans libraries. To ascertain interactions, the gap repair technique was performed as in [54].

\section{Plasmid construction}

To generate prey-tagged expression vectors used in coimmunoprecipitation assay or immunofluorescence, the coding regions of various genes were amplified by PCR using as template the corresponding EST clones obtained from RZPD (Berlin, Germany) and then inserted in the expression vectors using Gateway technology (Invitrogen, Carlsbad, CA). 
LET-756::GFP was obtained as previously described [16].

\section{Cell culture and in vivo interaction assay}

Cos- 1 cells grown in DMEM supplemented with $10 \%$ fetal calf serum were plated in 60-mm dishes at a concentration of $2 \times 10^{6} \mathrm{cells} /$ dish and immediately transfected with $1 \mu \mathrm{g}$ DNA in Fugene, according to the manufacturer instructions. Twenty four hours after transfection, cells were lysed in $1 \mathrm{ml}$ triton buffer (10 mM Tris, pH7.4, $100 \mathrm{mM}$ $\mathrm{NaCl}, 2.5 \mathrm{mM} \mathrm{MgCl} 2,1 \%$ triton, $1 \mathrm{mM}$ EDTA, $10 \mathrm{mM}$ DTT). Detergent insoluble materials were removed by 30 min centrifugation at $13000 \mathrm{rpm}$ at $4^{\circ} \mathrm{C}$. Whole cell lysates were first incubated with protein G-sepharose beads and then with the relevant antibody for at least $2 \mathrm{hr}$. Protein G-sepharose beads were then added for another additional $2 \mathrm{hr}$ and washed 3 times with lysis buffer. Bound proteins were eluted by boiling in SDS sample buffer and resolved on a 10\% SDS-PAGE gel and analyzed by Western blots. For immunofluorescence analysis, cells grown on glass coverslips were fixed and permeabilized in $3.7 \%$ PAF and $0.1 \%$ Triton or in methanol for $6 \mathrm{~min}$ at $20^{\circ} \mathrm{C}$. Similar results were obtained using these different modes of fixation. Cells were incubated with primary antibody for $1 \mathrm{hr}$ and then incubated with Texas Red-conjugated secondary antibody for another hr. Plasmid LET756::GFP was visualized by autofluorescence. Coverslips were examined using a Leica TCS NT confocal microscope.

The following antibodies were used: rat monoclonal antiHA (12CA5) antibody was from Roche (Indianopolis, IN, USA), rabbit polyclonal anti-GFP from Abcam (Cambridge, UK), Texas Red anti-rat antibody from Molecular Probes (Eugene, OR, USA), peroxydase anti-mouse from Santa Cruz (Santa Cruz, CA, USA)

\section{Abbreviations}

DMEM, Dulbecco's mofied Eagle's medium; FBS, fetal bovine serum; DTT dithiotreitol; Y2H, yeast two hybrid; GFP, green fluorescent protein

\section{Authors' contributions}

$\mathrm{CP}, \mathrm{YB}$ and $\mathrm{AH}$ performed the two-hybrid screenings and the analyses of the data, $\mathrm{CP}$ and FC the gap-repair confirmation of clones, FC and RR the co-immunoprecipitation and immunofluorescence experiments, CP the art work. $\mathrm{CP}$ played the major role in the bioinformatics analysis. DB initiated the C. elegans project and helped draft the manuscript. RR conceived and coordinated the study and wrote the manuscript. All authors read and approved the final manuscript.

\section{Acknowledgements}

We thank F. Birg and D. Maraninchi for encouragements, P. Pontarotti for helpful discussions, P. Lecine for advices during this study and J. Reboul for the gift of the ORFeome library and advices. The work has been supported by Inserm, Institut Paoli-Calmettes and grants from the Ligue Nationale Contre le Cancer (Label).

\section{References}

I. Goldfarb M: Functions of fibroblast growth factors in vertebrate development. Cytokine Growth Factor Rev 1996, 7:3 I I-325.

2. Dickson C, Spencer-Dene B, Dillon C, Fantl V: Tyrosine kinase signalling in breast cancer: fibroblast growth factors and their receptors. Breast Cancer Res 2000, 2:191-196.

3. Goldfarb $\mathrm{M}$ : Signaling by fibroblast growth factors: the inside story. SCi STKE 200I, I06:PE37.

4. Kolpakova E, Wiedlocha A, Stenmark H, Klingenberg O, Falnes PO, Olsnes $\mathrm{S}$ : Cloning of an intracellular protein that binds selectively to mitogenic acidic fibroblast growth factor. Biochem J 1998, 336:213-222

5. LaVallee TM, Tarantini F, Gamble S, Mouta Carreira C, Jackson A, Maciag T: Synaptotagmin-I is required for fibroblast growth factor-I release. J Biol Chem 1998, 273:222 I7-22223.

6. Burrus LW, Zuber ME, Lueddecke BA, Olwin BB: Identification of a cysteine-rich receptor for fibroblast growth factors. Mol Cell Biol 1992, I 2:5600-5609.

7. Kohl R, Antoine M, Olwin BB, Dickson C, Kiefer P: Cysteine-rich fibroblast growth factor receptor alters secretion and intracellular routing of fibroblast growth factor 3. J Biol Chem 2000, 275: I574|-|5748.

8. Kamikura DM, Cooper JA: Lipoprotein receptors and a disabled family cytoplasmic adaptor protein regulate EGL-I7/FGF export in C. elegans. Genes Dev 2003, I 7:2798-28II.

9. Bonnet $\mathrm{H}$, Filhol O, Truchet I, Brethenou P, Cochet C, Amalric F, Bouche G: Fibroblast growth factor-2 binds to the regulatory beta subunit of CK2 and directly stimulates CK2 activity toward nucleolin. J Biol Chem 1996, 27 I:2478I-24787.

10. Gringel S, van Bergeijk J, Haastert K, Grothe C, Claus P: Nuclear fibroblast growth factor-2 interacts specifically with splicing factor SF3a66. Biol Chem 2004, 385: I 203-1208.

II. Bossard C, Van den Berghe L, Laurell H, Castano C, Cerutti M, Prats AC, Prats $\mathrm{H}$ : Antiangiogenic properties of fibstatin, an extracellular FGF-2-binding polypeptide. Cancer Res 2004, 64:7507-75I 2.

12. Peng H, Sahni A, Fay P, Bellum S, Prudovsky I, Maciag T, Francis CW: Identification of a binding site on human FGF-2 for fibrinogen. Blood 2004, 103:21 |4-2120.

13. Birnbaum D, Popovici C, Roubin R: A pair as a minimum: The two fibroblast growth factors of the nematode Caenorhabditis elegans. Dev Dyn 2005, 232:247-255.

14. Huang P, Stern MJ: FGF signaling in flies and worms: more and more relevant to vertebrate biology. Cytokine Growth Factor Rev 2005, 16:I5I-I58.

15. Roubin R, Naert K, Popovici C, Vatcher G, Coulier F, Thierry-Mieg J, Pontarotti P, Birnbaum D, Baillie D, Thierry-Mieg D: let-756, a C. elegans fgf essential for worm development. Oncogene 1999 , | 8:674|-6747.

16. Popovici C, Conchonaud F, Birnbaum D, Roubin R: Functional phylogeny relates LET-756 to FGF9. J Biol Chem 2004, 279:40|46-40। 52.

17. Huang $P$, Stern MJ: FGF signaling functions in the hypodermis to regulate fluid balance in C. elegans. Development 2004, | 3 | :2595-2604.

18. Bulow HE, Boulin T, Hobert O: Differential functions of the $C$. elegans FGF receptor in axon outgrowth and maintenance of axon position. Neuron 2004, 42:367-374.

19. Popovici C, Fallet M, Marguet D, Birnbaum D, Roubin R: Intracellular trafficking of LET-756, a fibroblast growth factor of C. elegans, is controlled by a balance of export and nuclear signals. Exp Cell Res 2006, 3 I 2: I 484- I495.

20. Reboul J, Vaglio P, Rual JF, Lamesch P, Martinez M, Armstrong CM, Li S, Jacotot L, Bertin N, Janky R, Moore T, Hudson JR Jr, Hartley JL, Brasch MA, Vandenhaute J, Boulton S, Endress GA, Jenna S, Chevet E, Papasotiropoulos V, Tolias PP, Ptacek J, Snyder M, Huang R, Chance $M R$, Lee H, Doucette-Stamm L, Hill DE, Vidal M: C. elegans ORFeome version I.I: experimental verification of the genome annotation and resource for proteome-scale protein expression. Nat Genet 2003, 34:35-4I.

21. Baugh LR, Hill AA, Claggett JM, Hill-Harfe K, Wen JC, Slonim DK, Brown EL, Hunter CP: The homeodomain protein PAL-I spec- 
ifies a lineage-specific regulatory network in the $C$. elegans embryo. Development 2005, I32:1843-1854.

22. Birnby DA, Link EM, Vowels JJ, Tian H, Colacurcio PL, Thomas JHA Transmembrane guanylyl cyclase (DAF-II) and Hsp90 (DAF-2I) regulate a common set of chemosensory behaviors in Caenorhabditis elegans. Genetics 2000, I 55:85-I 04.

23. Inoue T, Takamura K, Yamae H, Ise N, Kawakami M, Tabuse Y, Miwa J, Yamaguchi Y: Caenorhabditis elegans DAF-2I (HSP90) is characteristically and predominantly expressed in germline cells: spatial and temporal analysis. Dev Growth Differ 2003, 45:369-376.

24. Nayak S, Santiago FE, Jin H, Lin D, Sched T, Kipreos ET: The Caenorhabditis elegans SkpI-related gene family: diverse functions in cell proliferation, morphogenesis, and meiosis. Curr Biol 2002, 12:277-287.

25. Yamanaka A, Yada M, Imaki H, Koga M, Ohshima Y, Nakayama K: Multiple Skpl-related proteins in Caenorhabditis elegans: diverse patterns of interaction with Cullins and F-box proteins. Curr Biol 2002, I 2:267-275.

26. Popovici C, Roubin R, Coulier F, Birnbaum D: An evolutionary history of the FGF superfamily. Bioessays 2005, 27:849-857.

27. Itoh N, Ornitz DM: Evolution of the Fgf and Fgfr gene families. Trends Genet 2004, 20:563-569.

28. Van Criekinge W, Beyaert R: Yeast Two-Hybrid: State of the Art. Biol Proced Online 1999, 2: I-38.

29. Burdine RD, Chen EB, Kwok SF, Stern MJ: egl- I 7 encodes an invertebrate fibroblast growth factor family member required specifically for sex myoblast migration in Caenorhabditis elegans. Proc Natl Acad Sci USA 1997, 94:2433-2437.

30. Aitken $A: \mathbf{1 4 - 3 - 3}$ and its possible role in co-ordinating multiple signalling pathways. Trends Cell Biol 1996, 6:34I-347.

31. Bridges D, Moorhead GB: 14-3-3 proteins: a number of functions for a numbered protein. SCi STKE 2005, 296:rel0.

32. Pellettieri J, Seydoux G: Anterior-posterior polarity in C. elegans and Drosophila - PARallels and differences. Science 2002, 298: 1946-1950.

33. Pownall ME, Tucker AS, Slack JM, Isaacs HV: eFGF, Xcad3 and Hox genes form a molecular pathway that establishes the anteroposterior axis in Xenopus. Development 1996, I 22:388I-3892.

34. Isaacs HV, Pownall ME, Slack JM: Regulation of Hox gene expression and posterior development by the Xenopus caudal homologue Xcad3. EMBO I 1998, 17:34|3-3427.

35. Edgar LG, Carr S, Wang H, Wood WB: Zygotic expression of the caudal homolog pal- $I$ is required for posterior patterning in Caenorhabditis elegans embryogenesis. Dev Biol 200I, 229:7I-88.

36. Shen $B$, Arese M, Gualandris A, Rifkin DB: Intracellular association of FGF-2 with the ribosomal protein L6/TAXREBI07. Biochem Biophys Res Commun 1998, 252:524-528.

37. Soulet F, Al Saati T, Roga S, Amalric F, Bouche G: Fibroblast growth factor-2 interacts with free ribosomal protein SI9. Biochem Biophys Res Commun 200I, 289:59I-596.

38. Skjerpen CS, Wesche J, Olsnes S: Identification of ribosomebinding protein $\mathrm{p} 34$ as an intracellular protein that binds acidic fibroblast growth factor. J Biol Chem 2002, 277:23864-2387I.

39. Mizukoshi E, Suzuki M, Loupatov A, Uruno T, Hayashi H, Misono T, Kaul SC, Wadhwa R, Imamura T: Fibroblast growth factor-I interacts with glucose-regulated protein GRP75/mortalin. Biochem J 1999, 343:46I-466.

40. Ananyeva N, Tjurmin A, Saenko E, Haudenschild C: Low density lipoproteins interact with acidic fibroblast growth factor and modify its function. Arterioscler Thromb Vasc Biol 2003, 23:60 I-607.

4I. Carreira CM, LaVallee TM, Tarantini F, Jackson A, Lathrop JT, Hampton B, Burgess WH, Maciag T: SI O0A 33 Is Involved in the Regulation of Fibroblast Growth Factor-I and $\mathbf{4 0}$ Synaptotagmin-I Release in Vitro. I Biol Chem 1998, 273:22224-22231.

42. Tassi E, Al-Attar A, Aigner A, Swift MR, McDonnell K, Karavanov A, Wellstein A: Enhancement of fibroblast growth factor (FGF) activity by an FGF-binding protein. J Biol Chem 200I, 276:40247-40253.

43. Wiedlocha A, Falnes PO, Madshus IH, Sandvig K, Olsnes S: Dual mode of signal transduction by externally added acidic fibroblast growth factor. Cell 1994, 76:1039-105I.
44. Bossard C, Laurell H, Van den Berghe L, Meunier S, Zanibellato C, Prats $\mathrm{H}$ : Translokin is an intracellular mediator of FGF-2 trafficking. Nat Cell Biol 2003, 5:433-439.

45. Claus P, Doring F, Gringel S, Muller-Ostermeyer F, Fuhlrott J, Kraft $\mathrm{T}$, Grothe C: Differential intranuclear localization of fibroblast growth factor-2 isoforms and specific interaction with the survival of motoneuron protein. J Biol Chem 2003, 278:479-485.

46. Claus P, Bruns AF, Grothe C: Fibroblast growth factor-2(23) binds directly to the survival of motoneuron protein and is associated with small nuclear RNAs. BiochemJ 2004, 384:559-565.

47. Sahni A, Khorana AA, Baggs RB, Peng H, Francis CW: FGF-2 binding to fibrin(ogen) is required for augmented angiogenesis. Blood 2006, 107:|26-|3|

48. Van den Berghe L, Laurell $\mathrm{H}$, Huez I, Zanibellato $\mathrm{C}$, Prats $\mathrm{H}$, Bugler $\mathrm{B}$ FIF [fibroblast growth factor-2 (FGF-2)-interacting-factor], a nuclear putatively antiapoptotic factor, interacts specifically with FGF-2. Mol Endocrinol 2000, 14:1709-1724.

49. Camozzi M, Zacchigna S, Rusnati M, Coltrini D, Ramirez-Correa G, Bottazzi B, Mantovani A, Giacca M, Presta M: Pentraxin 3 inhibits fibroblast growth factor 2-dependent activation of smooth muscle cells in vitro and neointima formation in vivo. Arterioscler Thromb Vasc Biol 2005, 25: 1837-1842.

50. Chadderton NS, Stringer SE: Interaction of platelet factor $\mathbf{4}$ with fibroblast growth factor $\mathbf{2}$ is stabilised by heparan sulphate. Int J Biochem Cell Biol 2003, 35: 1052-1055.

51. Reimers K, Antoine M, Zapatka M, Blecken V, Dickson C, Kiefer P: NoBP, a nuclear fibroblast growth factor 3 binding protein, is cell cycle regulated and promotes cell growth. Mol Cell Biol 200I, $21: 4996-5007$.

52. Schoorlemmer J, Goldfarb M: Fibroblast growth factor homologous factors and the islet brain-2 scaffold protein regulate activation of a stress-activated protein kinase. J Biol Chem 2002, 277:49|||-49|| 9

53. Vaglio P, Lamesch P, Reboul J, Rual JF, Martinez M, Hill D, Vidal M: The Caenorhabditis elegans ORFeome Database. Nucleic Acids Res 2003, I:3|237-3/240.

54. Walhout AJ, Vidal M: High-throughput yeast two-hybrid assays for large-scale protein interaction mapping. Methods 200I, 24:297-306.

55. Hu J, Bae YK, Knobel KM, Barr MM: Casein Kinase II and Calcineurin Modulate TRPP Function and Ciliary Localization. Mol Biol Cell 2006, I7:2200-22II.

56. [http://nematode.lab.nig.ac.jp/db2/].

57. [http://elegans.bcgsc.ca/perl/eprofile/index].

58. [http://www.wormbase.org].
Publish with Biomed Central and every scientist can read your work free of charge

"BioMed Central will be the most significant development for disseminating the results of biomedical research in our lifetime. "

Sir Paul Nurse, Cancer Research UK

Your research papers will be:

- available free of charge to the entire biomedical community

- peer reviewed and published immediately upon acceptance

- cited in PubMed and archived on PubMed Central

- yours - you keep the copyright
BioMedcentral 